\title{
Experimental study on thermal performance in three-flow cooling tower
}

\author{
Ilnur Madyshev 1,*, Ildar Sabanaev², Vitaly Kharkov ${ }^{1}$, Lenar Ganiev², and Andrey Dmitriev ${ }^{3}$ \\ ${ }^{1}$ Kazan National Research Technological University, 420015, Karl Marx street 68, Kazan, Russia \\ ${ }^{2}$ Nizhnekamsk Institute of Chemical Technology, 423578, Stroiteley street 47, Nizhnekamsk, Russia \\ ${ }^{3}$ Kazan State Power Engineering University, 420066, Krasnoselskaya street 51, Kazan, Russia
}

\begin{abstract}
Biofouling can significantly deteriorate the efficiency of cooling towers. A cooling tower with a three-flow cooling circuit has been developed. The fill pack consists of inclined-corrugated contact elements with perforation. One of the advantages of the proposed cooling tower is the possibility of uniform distribution of liquid over the cross-sectional area. The paper represents the results of an experimental study of the thermal performance of the three-flow cooling tower. It was found that when the wetting rate of the liquid increases, the thermal performance of the cooling tower can reach $47.8 \%$. The developed three-flow cooling tower allows excluding the propagation of microorganisms and reducing the biofouling of industrial water systems along with the high performance for circulating water.
\end{abstract}

\section{Introduction}

Pure cold water is a valuable resource in the current chemical and petrochemical industries. In line with energy-saving and water consumption trends, every plant requires efficient water circulation systems, including the purification and cooling processes. For these purposes, various equipment is used, for example, cooling towers, due to their simplicity, reliability, and sufficient efficiency. Despite these advantages, R\&D proceeds to improve the cooling process in such devices, where two distinct directions can be emphasized. First, further improving the thermal performance of the device and technology [1,2]. Second, the development of specific technologies for combating contamination of equipment by various microorganisms $[3,4]$.

Biofouling can result in a reduction in the overall effectiveness of the tower with time. Cooling towers provide optimal conditions, such as temperature, $\mathrm{pH}$ value, growthsupporting medium, and sunlight, for the active growth of different microorganisms $[5,6]$. The lower sections of the cooling towers are suitable for the population of large filamentous algae, the central part contains plankton algae, and biofilms of cyanobacteria colonize the upper part. Various chemicals can be used to control microorganisms, for example, common bleach chloride. However, chlorine-containing substances produce a somewhat negative effect due to their high chemical activity [7]. They oxidize steel elements of equipment no

* Corresponding author: $\underline{\text { ilnyr_91@mail.ru }}$ 
less than a biofilm. The study [8] has been carried out using a specially designed setup with glutaraldehyde as a reagent against planktonic and biofilm microbial communities.

Authors [9] pointed out that the biofilm, except aggressive acting on equipment elements, forms layers with low thermal conductivity, which leads to deterioration of the heat transfer process. Moreover, the microorganism layer has a higher thermal resistance than calcium carbonate.

The analysis and classification of the microorganisms populating the cooling tower and the efficiency of using various reagents for cleaning from biofouling were performed in [10]. For instance, Bromonitropropanediol handles fungi and algae well but is ineffective against cyanobacteria. Beta-Bromo-beta-nitrostyrene suppresses the growth of all bacteria, including cyanobacteria, but does not affect fungal cultures. Methylene dithiocyanate is optimal for inhibiting microalgae. They concluded that the significant reduction of biological contaminants involves monitoring their quality composition and an integrated approach to reagent selection.

The authors of the work [11] developed a special biofilter with a fixed layer, which allows removing all organic matter from the cooled water, which significantly limits the growthsupporting medium for microorganisms. Comparing the study results at the model setup with bio-contamination similar to the industrial cooling tower showed their 30-40-x decrease.

Various studies have been devoted to enhancing the thermal performance of cooling towers $[12,13]$. For example, according to [14], the operational support system's use with the proposed process optimization model leads to annual energy savings for the water-cooling US plant in the amount of about $9.67 \%$. The authors emphasize that the result was achieved without changing the plant control system. Paper [15] states that for every $10^{\circ} \mathrm{F}$ decrease in the water temperature, $1 \%$ of its total mass is lost due to evaporation. The authors presented the results of studying the influence of different factors on this phenomenon, which makes it possible to select operating conditions that minimize the entrainment of vapors. And last but not least, when designing the new cooling towers, the crucial factor is to select the optimal design of the fill pack, which can intensify heat and mass transfer processes between interacting phases and decrease the amount of droplet entrainment with minimal energy resources [16-25].

So far, a novel fill pack has been developed, consisting of inclined-corrugated contact elements [26]. A previous study of the dynamics of liquid and gas flows [27,28] showed the possibility of uniform distribution of liquid along the cooling tower's cross-sectional area. According to [29], the entrainment of liquid droplets from the fill pack at an average gas velocity of 1.5 to $2.4 \mathrm{~m} / \mathrm{s}$ does not exceed $5 \%$. A new circuit of operation of the cooling tower has been developed to solve the problem of biofouling in cooling towers. Specifically, a tubular radiator is installed inside the cooling tower fill pack to prevent mixing the main liquid flow with atmospheric air. As a result, the growth of microorganism groups in water without oxygen becomes practically impossible. With this cooling water method, industrial enterprises can significantly reduce the use of chemicals and even eliminate them. Therefore, in the present work, the three-flow cooling tower performance is experimentally investigated on the water-air system.

\section{Experimental methodology}

The experimental system used here is shown in Fig. 1. The operating principle of the proposed three-flow cooling tower for circulating water is as follows. The water heated in the process equipment before entering the cooling tower is divided into two flows. Note that the rate of the first flow substantially exceeds the second flow rate. The first flow is supplied to the tubular radiator, avoiding direct contact with atmospheric air. 
The second flow goes into the upper part of the fill pack, contacts atmospheric air, partially evaporates, and eventually collects in the water tank. Cooling of the first water flow occurs due to heat transfer from the radiator wall to air and the liquid washing over the tubes. Besides, the washing liquid consisted of cooled water and fresh make-up water. Water is pumped into the cooling tower from the tank, providing a closed circuit of coolant water.

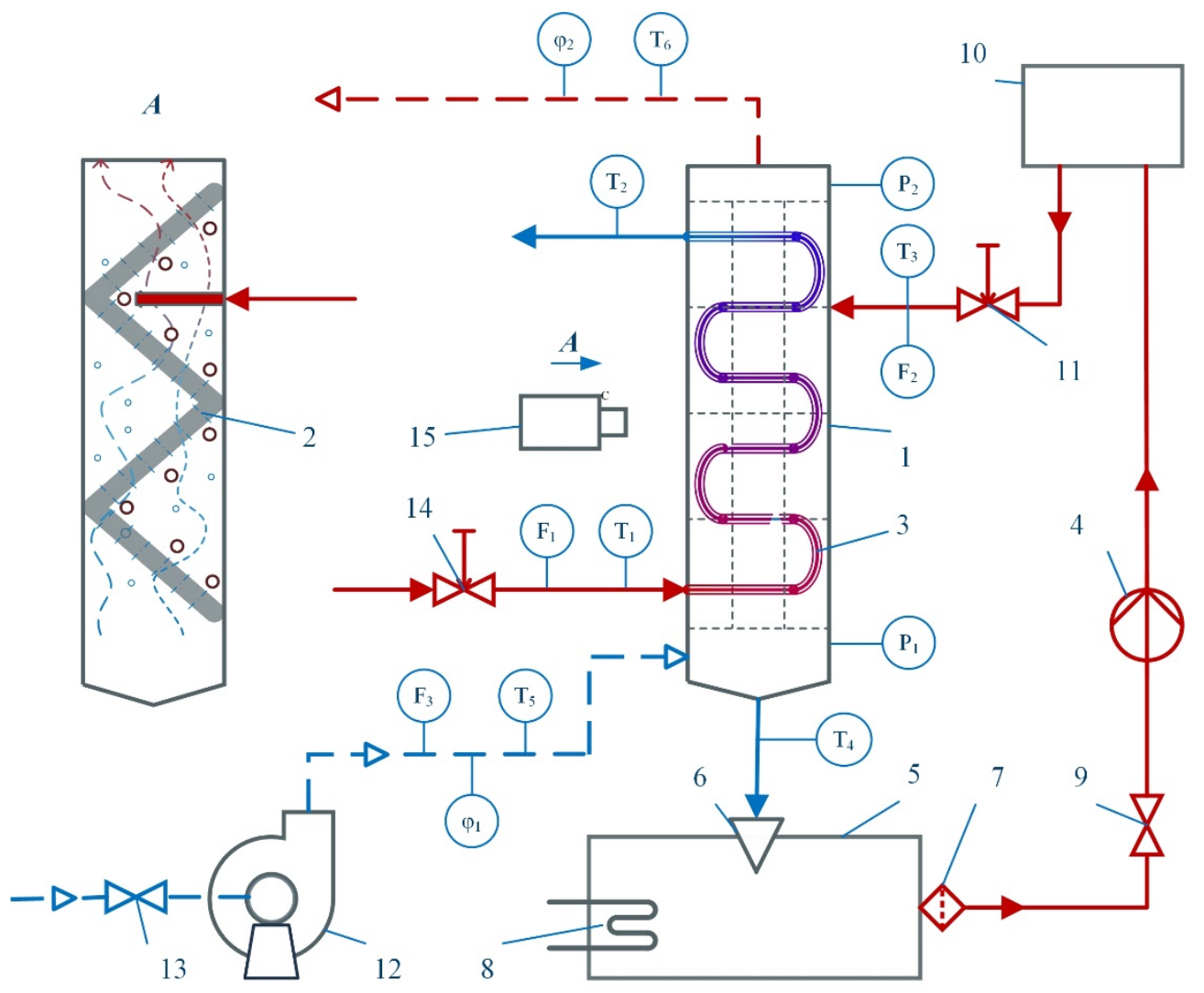

Fig. 1. Schema of the experimental system: 1 - fill pack; 2 - inclined-corrugated contact elements; 3 water distributor; 4 - pump; 5,10 - water tank; 6 - funnel; 7 - liquid filter; 8 - heaters; $9,11,14$ shutoff valves on the water supply line; 12 - fan; 13 - shutoff valves in the air supply line; 15 - camera.

Experiments were conducted on the water-air system to estimate the performance of the cooling water in the developed three-flow tower. The experimental setup (Fig. 2) is the fill pack consisting of four inclined-corrugated plates with $6 \mathrm{~mm}$ in diameter holes and a total height of $340 \mathrm{~mm}$. The cross-section of the test area was $100 \mathrm{~mm} \times 100 \mathrm{~mm}$. The corrugated plates are made of steel with a thickness of $0.6 \mathrm{~mm}$ and a radius of curvature of $7.5 \mathrm{~mm}$. Round holes with an 11-12 mm pitch for liquid and gas flows are drilled on side surfaces and top of plate corrugations. Besides, round holes $3 \mathrm{~mm}$ in diameter and a pitch of $10 \mathrm{~mm}$ are also made in corrugations troughs. The fill pack has 30 copper tubes with a diameter of $8 \mathrm{~mm}$ and a length of $125 \mathrm{~mm}$, connected using silicone tubing. Tubes are mounted across inclined corrugated plates. 


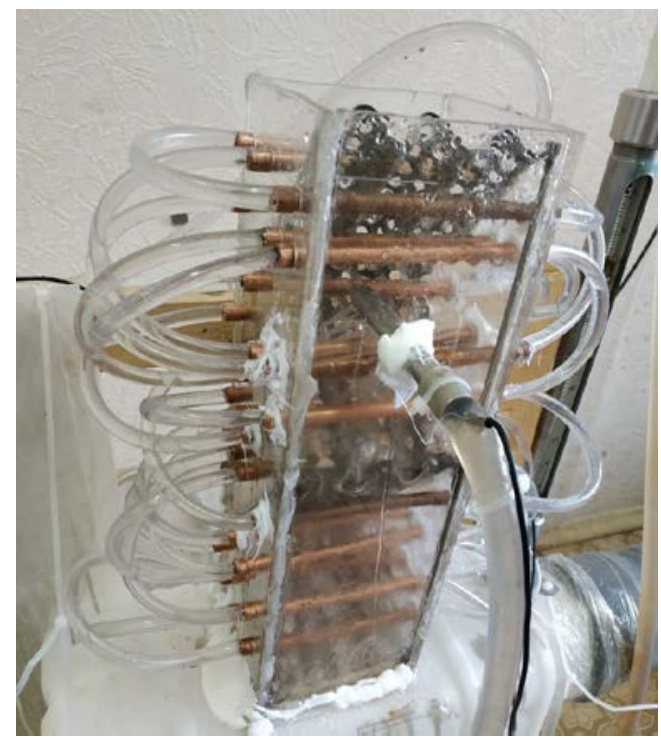

Fig. 2. Image of the fill pack with inclined-corrugated contact elements and three-flow cooling circuit.

The liquid distributes in the volume of the fill pack as follows. Water flows from top to bottom, washes above the surface of the pipes, removing heat, and in the form of a film, the liquid flows down the perforated plate, forming a zigzag trajectory. Part of the liquid falls through the plate's holes, break up into droplets, which hit the surface of the liquid film of the underlying plate and pipes, are repeatedly break up, creating new spray droplets. The fan blows the air from bottom to top, passes through the holes in the plates, and pushes water droplets in different directions, thereby spraying liquid over the entire volume of the fill pack and outer pipe surfaces. It should be noted that the upper-located plates serve as separation devices that reduce the amount of entrainment of liquid droplets from the cooling tower.

For further details, the data of all employed measuring devices in the experimental setup are listed in Table 1.

Table 1. Specification of measuring sensors.

\begin{tabular}{|c|c|c|c|}
\hline Parameter & Sensor & Range & Accuracy \\
\hline $\begin{array}{l}\text { Average velocity of } \\
\text { colling air }\end{array}$ & $\begin{array}{l}\text { Hot-wire anemometer } \\
\text { TESTO 405i }\end{array}$ & $1.55-3.94 \mathrm{~m} / \mathrm{s}$ & $\begin{array}{c} \pm(0.1 \mathrm{~m} / \mathrm{s}+5 \% \text { of mean } \\
\quad \text { value })(0 \text { to } 2 \mathrm{~m} / \mathrm{s}) \\
\pm(0.3 \mathrm{~m} / \mathrm{s}+5 \% \text { of mean } \\
\text { value })(2 \text { to } 15 \mathrm{~m} / \mathrm{s})\end{array}$ \\
\hline Air temperature & \multirow{2}{*}{$\begin{array}{c}\text { Thermohygrometer } \\
\text { TESTO } 605 \mathrm{i}\end{array}$} & $28.4-31.3^{\circ} \mathrm{C}$ & $\pm 0.5^{\circ} \mathrm{C}$ \\
\hline $\begin{array}{l}\text { Relative humidity } \\
\text { (RH) }\end{array}$ & & $46.0-54.8 \%$ & $\begin{array}{c} \pm 3.0 \% \mathrm{RH}(10 \text { to } \\
35 \% \mathrm{RH}) \\
\pm 2.0 \% \mathrm{RH}(35 \text { to } \\
65 \% \mathrm{RH})\end{array}$ \\
\hline $\begin{array}{l}\text { Water temperature } \\
\text { in tubular radiator }\end{array}$ & $\begin{array}{l}\text { Meter-regulator } \\
\text { OWEN 2TRM1 }\end{array}$ & $33.3-43.8^{\circ} \mathrm{C}$ & $\pm 0.5 \%$ \\
\hline $\begin{array}{l}\text { Temperature of } \\
\text { washing water }\end{array}$ & $\begin{array}{l}\text { Meter-regulator } \\
\text { OWEN 2TRM1 }\end{array}$ & $25.2-37.5^{\circ} \mathrm{C}$ & $\pm 0.5 \%$ \\
\hline Wetting rate & $\begin{array}{l}\text { Rotameter LZB- } \\
\text { VA10-15F }\end{array}$ & $11.8-36.8 \mathrm{~m}^{3} /\left(\mathrm{m}^{2} \cdot \mathrm{h}\right)$ & $\pm 1.5 \%$ \\
\hline $\begin{array}{l}\text { Water flow rate in } \\
\text { tubular radiator }\end{array}$ & $\begin{array}{c}\text { Flow meter Betar } \\
\text { SGV-15 }\end{array}$ & $0.13-0.42 \mathrm{~kg} / \mathrm{s}$ & $\pm 2.0 \%$ \\
\hline
\end{tabular}




\section{Results and discussion}

The main evaluation criterion of heat and mass transfer processes in the cooling tower is thermal performance, which reflects the fill packs' perfection. So, the thermal performance $\eta_{L}$ of the three-flow evaporative cooling tower can be expressed by changing the temperature difference of the main water flow by Eq. (1).

$$
\eta_{L}=\frac{T_{1}-T_{2}}{T_{1}-T_{e q}},
$$

where $T_{1}$ and $T_{2}$ are water temperature at the inlet and outlet to the tubular radiator, respectively, ${ }^{\circ} \mathrm{C} ; T_{e q}$ is the equilibrium water temperature (dew point temperature), ${ }^{\circ} \mathrm{C}$.

Besides, cooling of the main flow of liquid entering the tubular radiator is summed by simultaneous cooling of the wetting liquid due to the counterflow air and heat transfer through the radiator wall surface. The following equation can estimate the performance of the heat transfer process from the reflux liquid to the main flow $\eta_{L}^{\prime \prime}$ :

$$
\eta_{L}^{\prime \prime}=\frac{T_{1}-T_{2}}{T_{1}-T_{4}}
$$

where $T_{4}$ is the water temperature at the outlet of the fill pack, ${ }^{\circ} \mathrm{C}$.

The experimental data results showed that the performance in the three-flow cooling tower depends significantly on the wetting rate of the cooling liquid and the flow rate of the main water flow in the tubular radiator. It was found that with an increase in the wetting rate of the cooling liquid, the performance of heat and mass transfer processes in the three-flow cooling tower rises. For example, the average efficiency of heat transfer through the radiator is $93.7 \%$ at the wetting rate of $36.8 \mathrm{~m}^{3} /\left(\mathrm{m}^{2} \cdot \mathrm{h}\right)$, and the mass flow rate of water in the pipes of $0.13 \mathrm{~kg} / \mathrm{s}$ (Fig. $3 \mathrm{a}, \mathrm{b})$.

The results of experiments on the influence of the mass flow rate of liquid in the tubular radiator on the thermal performance of a three-flow cooling tower are shown in Fig. 4. The performance increases with decreasing liquid flow rate in the pipes, and this dependence is well consistent with the heat balance equation of cooling towers. For instance, at the average air velocity of $2.0 \mathrm{~m} / \mathrm{s}$ and the wetting rate of $11.8 \mathrm{~m}^{3} /\left(\mathrm{m}^{2} \cdot \mathrm{h}\right)$, a decrease in the mass flow rate of liquid in pipes from $0.422 \mathrm{~kg} / \mathrm{s}$ to $0.13 \mathrm{~kg} / \mathrm{s}$ leads to an increase in thermal performance by $24.1 \%$.
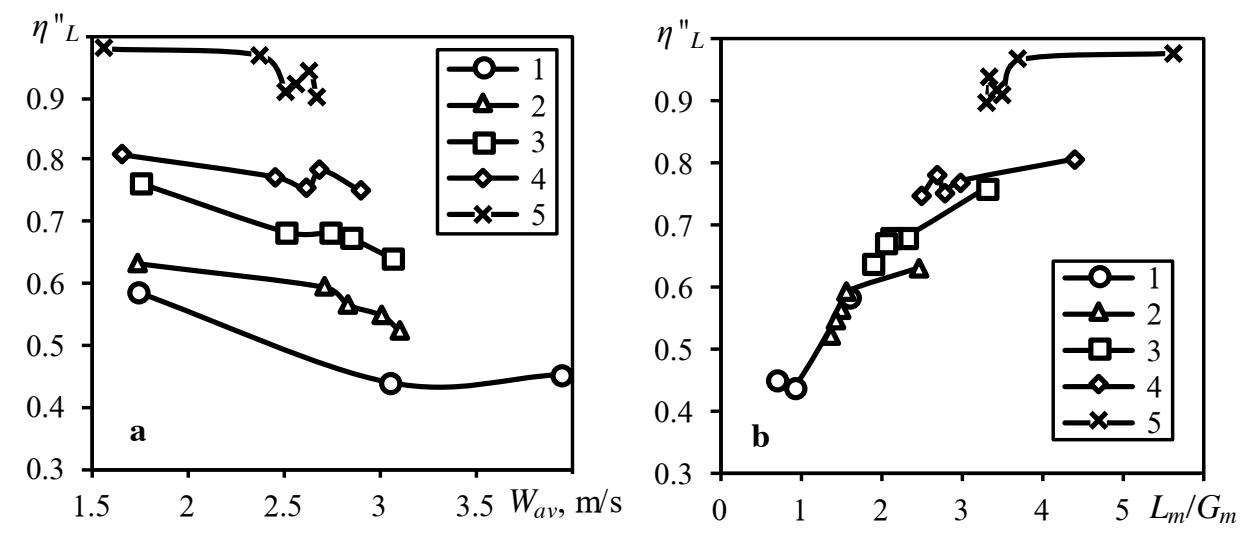

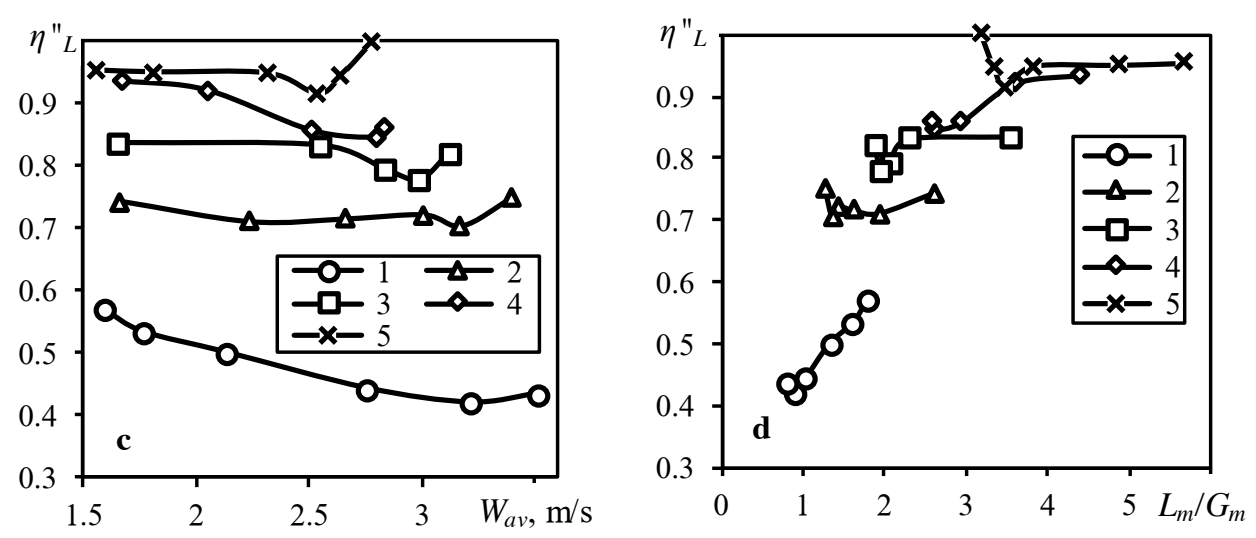

Fig. 3. The heat transfer performance through the radiator wall in the three-flow cooling tower against the average gas velocity $(\mathrm{a}, \mathrm{c})$ and the mass flow rate ratio $(\mathrm{b}, \mathrm{d})$ at the different wetting rates $q$, $\mathrm{m}^{3} /\left(\mathrm{m}^{2} \cdot \mathrm{h}\right): 1-11.8 ; 2-18.0 ; 3-24.3 ; 4-30.6 ; 5-36.8$. The average mass flow rate of the water in the tubular radiator: $\mathrm{a}, \mathrm{b}-0.13 \mathrm{~kg} / \mathrm{s} ; \mathrm{c}, \mathrm{d}-0.422 \mathrm{~kg} / \mathrm{s}$.

Note a significant increase in the performance of the three-flow cooling tower with an increase in the wetting rate of the cooling liquid. Thus, an increase in the wetting rate from 11.8 to $36.8 \mathrm{~m}^{3} /\left(\mathrm{m}^{2} \cdot \mathrm{h}\right)$ at the average air velocity of $2.0 \mathrm{~m} / \mathrm{s}$ leads to an increase in the thermal performance of the proposed cooling tower by $31.3 \%$ (Fig. 4 a).
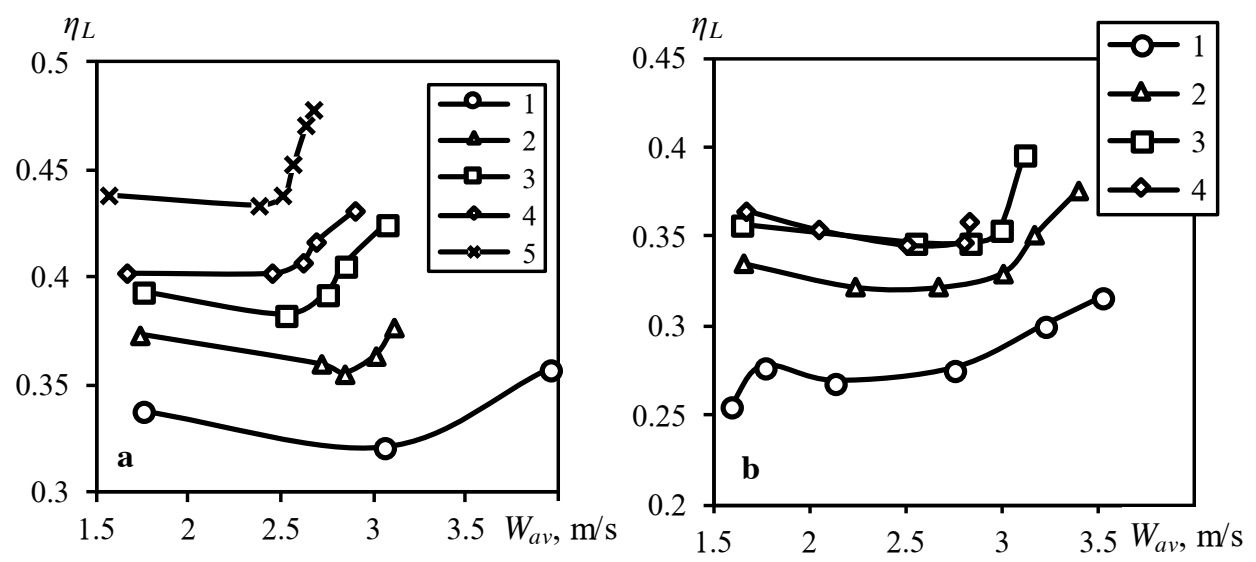

Fig. 4. Thermal performance of the three-flow cooling tower against the average gas velocity at the different wetting rates $q, \mathrm{~m}^{3} /\left(\mathrm{m}^{2} \cdot \mathrm{h}\right): 1-11.8 ; 2-18.0 ; 3-24.3 ; 4-30.6 ; 5-36.8$. The average mass flow rate of the water in the tubular radiator: $\mathrm{a}-0.13 \mathrm{~kg} / \mathrm{s} ; \mathrm{b}-0.422 \mathrm{~kg} / \mathrm{s}$.

\section{Conclusion}

The present study investigates the thermal performance of the three-flow cooling tower with the fill pack, consisting of the inclined-corrugated contact elements. The study yields the following conclusions:

- the proposed device makes possible of cooling the main liquid flow of circulating water by 9.2-10.0 ${ }^{\circ} \mathrm{C}$ at an initial hot water temperature of $43.3-43.4^{\circ} \mathrm{C}$; 
- when the wetting rate of the liquid increases to $36.8 \mathrm{~m}^{3} /\left(\mathrm{m}^{2} \cdot \mathrm{h}\right)$, the thermal performance of the developed cooling tower can reach $47.8 \%$;

- the proposed three-flow circuit does not lead to a decrease in gas flow capacity since the flooding velocity is $2.4-3.2 \mathrm{~m} / \mathrm{s}$ depending on the wetting rate.

Thus, the developed three-flow cooling tower for circulating water allows eliminating the growth of microorganisms, thereby reducing the working surfaces' biofouling and providing the high thermal performance of the cooling water systems of industrial enterprises.

The reported study was funded by the grant of the President of the Russian Federation, project number MK-417.2019.8.

\section{References}

1. M. Rahmati, S. R. Alavi, and M. R. Tavakoli, Energy Convers. Manag. 126, 971 (2016)

2. P. Imani-Mofrad, Z. H. Saeed, and M. Shanbedi, Energy Convers. Manag. 127, 199 (2016)

3. I. S. M. Pinel, D. H. Moed, J. S. Vrouwenvelder, and M. C. M. van Loosdrecht, Water Res. 172, 115505 (2020)

4. T. S. Rao, in Miner. Scales Depos. (Elsevier, 2015), pp. 123-140

5. I. Pagnier, M. Merchat, and B. Scola, Future Microbiol. 4, 615 (2009)

6. M. Ludensky, in Dir. Microbicides Prot. Mater. (2004), pp. 121-139

7. D. Daniels, Power (2015)

8. Y. Liu, W. Zhang, T. Sileika, R. Warta, N. P. Cianciotto, and A. I. Packman, Biofouling 27, 393 (2011)

9. A. J. Beber, in 2nd World Conf. Ind. Chem. Water Treat. (2017), p. 42

10. In Handb. Ind. Water Treat. (SUEZ, 2020)

11. K. P. H. Meesters, J. W. Van Groenestijn, and J. Gerritse, Water Res. 37, 525 (2003)

12. M. Gao, J. Zou, S. He, and F. Sun, Appl. Therm. Eng. 136, 568 (2018)

13. N. A. Merentsov, V. N. Lebedev, A. B. Golovanchikov, V. A. Balashov, and E. E. Nefed'eva, in IOP Conf. Ser. Earth Environ. Sci. (2018), p. 12017

14. S. Huang, W. Zuo, and M. D. Sohn, Build. Environ. 111, 33 (2017)

15. U. Vengateson, Chem. Eng. (2017)

16. A. B. Golovanchikov, N. A. Merentsov, and V. A. Balashov, Chem. Pet. Eng. 48, 595 (2013)

17. E. V. Boev, S. P. Ivanov, V. G. Afanasenko, and E. A. Nikolaev, Chem. Pet. Eng. 45, 454 (2009)

18. N. Merentsov, A. Persidskiy, V. Lebedev, N. Prokhorenko, and A. Golovanchikov, in (2019), pp. 547-559

19. O. S. Dmitrieva, I. N. Madyshev, and A. V. Dmitriev, J. Eng. Phys. Thermophys. 90, 651 (2017)

20. Madyshev, Ilnur N., Dmitrieva, Oksana S., and Dmitriev, Andrey V., MATEC Web Conf. 91, 1019 (2017)

21. Q. J. Kong, D. Y. Liu, P. Wang, D. Q. Xie, Q. Wu, and X. Y. Zhao, Thermophys. Aeromechanics 26, 267 (2019) 
22. M. Gao, L. Zhang, N. N. Wang, Y. T. Shi, and F. Z. Sun, Appl. Therm. Eng. 93, 549 (2016)

23. V. G. Afanasenko, F. S. Khafizov, N. F. Khafizov, S. P. Ivanov, and E. V. Boev, Chem. Pet. Eng. 43, 653 (2007)

24. N. Merentsov, V. Balashov, D. Bunin, V. Lebedev, A. Persidskiy, and M. Topilin, MATEC Web Conf. 243, 00011 (2018)

25. P. Shahali, M. Rahmati, S. R. Alavi, and A. Sedaghat, Int. J. Refrig. 65, 80 (2016)

26. A. V Dmitriev, I. N. Madyshev, A. I. Khafizova, V. V Kharkov, and M. R. Vakhitov, IOP Conf. Ser. Mater. Sci. Eng. 862, 62099 (2020)

27. I. N. Madyshev, A. I. Khafizova, and O. S. Dmitrieva, E3S Web Conf. 126, 00031 (2019)

28. O. S. Dmitrieva, A. V. Dmitriev, I. N. Madyshev, and A. N. Nikolaev, Chem. Pet. Eng. 53, 130 (2017)

29. I. Madyshev, V. Kharkov, and A. Dmitriev, E3S Web Conf. 193, 01044 (2020) 